\title{
Analysis of gene expression profiles in insulin-sensitive tissues from pre-diabetic and diabetic Zucker diabetic fatty rats
}

\author{
Young Ho Suh, Younyoung Kim, Jeong Hyun Bang, Kyoung Suk Choi, June Woo Lee, \\ Won-Ho Kim, Tae Jeong Oh ${ }^{1}$, Sungwhan $\mathrm{An}^{1}$ and Myeong Ho Jung
}

Division of Metabolic Diseases, Department of Biomedical Sciences, National Institute of Health, 5 Nokbun-dong, Eunpyung-gu, Seoul, 122-701, South Korea

${ }^{1}$ Research and Development, GenomicTree, Inc., 461-6 Jonmin-dong, Yusong-gu, Taejon 305-811, South Korea

(Requests for offprints should be addressed to M H Jung; Email: jung0603@ nih.go.kr)

\begin{abstract}
Insulin resistance occurs early in the disease process, preceding the development of type 2 diabetes. Therefore, the identification of molecules that contribute to insulin resistance and leading up to type 2 diabetes is important to elucidate the molecular pathogenesis of the disease. To this end, we characterized gene expression profiles from insulin-sensitive tissues, including adipose tissue, skeletal muscle, and liver tissue of Zucker diabetic fatty (ZDF) rats, a well characterized type 2 diabetes animal model. Gene expression profiles from ZDF rats at 6 weeks (pre-diabetes), 12 weeks (diabetes), and 20 weeks (late-stage diabetes) were compared with age- and sex-matched Zucker lean control (ZLC) rats using 5000 cDNA chips. Differentially regulated genes demonstrating $>1 \cdot 3$-fold change at age were identified and categorized through hierarchical clustering analysis. Our results showed that while expression of lipolytic genes was elevated in adipose tissue of diabetic ZDF rats at 12 weeks of age, expression of lipogenic genes was decreased in liver but increased in skeletal muscle of 12 week old diabetic ZDF rats.

These results suggest that impairment of hepatic lipogenesis accompanied with the reduced lipogenesis of adipose tissue may contribute to development of diabetes in ZDF rats by increasing lipogenesis in skeletal muscle. Moreover, expression of antioxidant defense genes was decreased in the liver of 12-week old diabetic ZDF rats as well as in the adipose tissue of ZDF rats both at 6 and 12 weeks of age. Cytochrome P450 (CYP) genes were also significantly reduced in 12 week old diabetic liver of ZDF rats. Genes involved in glucose utilization were downregulated in skeletal muscle of diabetic ZDF rats, and the hepatic gluconeogenic gene was upregulated in diabetic ZDF rats. Genes commonly expressed in all three tissue types were also observed. These profilings might provide better fundamental understanding of insulin resistance and development of type 2 diabetes.
\end{abstract}

Journal of Molecular Endocrinology (2005) 34, 299-315

\section{Introduction}

Type 2 diabetes mellitus is a common metabolic disease involving abnormal carbohydrate regulation and lipid metabolism by insulin (Saltiel 2001). Insulin resistance, characterized as decreased insulin action on glucose uptake and metabolism, occurs prior to the onset of type 2 diabetes and plays a major role in its development. Contributing to insulin resistance, obesity is known as a strong risk factor for type 2 diabetes. However, obesity alone does not account for disease development, as only a small fraction of obese people develop diabetes, with most being able to maintain a euglycemic state despite also being insulin resistant. Since it is likely that the development of type 2 diabetes is determined in part by genetic factors, understanding differences in gene expression of insulin-sensitive tissues from animals in different progressive stages of diabetes development (e.g. insulin resistant pre-diabetes and diabetes) may help uncover the underlying molecular mechanisms involved in disease progression.

A recent advancement in genomic research, microarray technology allows for the expression of thousands of genes to be quickly and easily monitored in parallel. Global gene expression, or transcriptional profiling, has been used to identify molecular markers for various pathological states and can be used to generate novel hypotheses to characterize different disease states. Studies using microarrays have been performed to identify candidate genes related to insulin resistance and diabetes in animal and human models of diabetes (Yang et al. 2002, Sreekumar et al. 2002, Lan et al. 2003, Rome et al. 2003, Mootha et al. 2003). However, until recently, there was no full set of alterations in gene expression that may possibly be involved in the disease pathology of type 2 diabetes. 
A well-characterized model of obesity and type 2 diabetes, the Zucker diabetic fatty (ZDF) rat, has a point mutation in the leptin receptor that leads to impairment of the signaling capabilities of this receptor. The $\mathrm{ZDF}$ rat develops an age-dependent diabetes phenotype, with onset of obesity at 5-7 weeks of age accompanied by a metabolic state of early diabetes mellitus with hyperinsulinemia and insulin resistance, but with euglycemia. The full syndrome of diabetes develops at 10-12 weeks with hyperglycemia. The diabetic pathogenetic features manifested in this animal model are in many ways reminiscent of the pathogenesis of type 2 diabetes in humans. Therefore, the ZDF animal model is ideal for identifying molecules contributing to insulin resistance related to obesity and to eludiate the molecular pathogenesis of type 2 diabetes.

In this study, using cDNA microarrays, global gene expression in adipose tissue, skeletal muscle, and liver tissue were profiled from 6-week old pre-diabetic ZDF rats, 12-week old diabetic ZDF rats and 20-week old late-stage diabetic ZDF rats compared with age and sex-matched Zucker lean control (ZLG) rats. This approach provided several candidate genes and possible molecular mechanisms responsible for insulin resistance and progression to type 2 diabetes.

\section{Materials and methods}

\section{Animals}

Male Zucker diabetic fatty (ZDF/Gmi- $f a / f a)$ rats $(6,12$ or 20 weeks old) and their sex- and age-matched Zucker lean control (ZLC/Gmi-+/fa) rats were purchased from Genetic Models (GMI, Indianapolis, IA, USA). Animals were maintained on a commercial chow diet ad libitum before being killed. Body weights and blood glucose levels for the 6- and 12-week old ZDF rats were pre-diabetic and diabetic stage-appropriate, respectively. The rats were sacrificed by cervical dislocation, and the epididymal fat, skeletal muscle of the femoral region, and liver were removed and subjected to total RNA extraction.

\section{RNA preparation and labeling}

Total RNA was isolated using the TRIzol reagent GibcoBRL, Invitrogen Corporation, Carlsbad, CA, USA). The cDNA were labeled with the 3DNA Array kit (Genisphere, Hatfield, PA, USA) according to the manufacturer's protocol and recommendations. The cDNA of ZDF rats was labeled with Cy5, and cDNA of each paired control ZLC rat was labeled with Cy3. Briefly, total RNA $(20 \mu \mathrm{g})$ and the Cy3 or Gy5 capture sequence primer were solubilized in $20 \mu \mathrm{l}$ of diethyl pyrocarbonate (DEPC)-treated water and incubated for
10 min at $80^{\circ} \mathrm{C}$. The RNA mixture was then transferred on to ice and the RNase inhibitor was added. An equal volume of reaction mixture containing $5 \mathrm{X}$ first-strand buffer, $100 \mathrm{mM}$ DTT, $10 \mathrm{mM}$ dNTP mix and 200 units of Superscript II reverse transcriptase (Invitrogen, Carlsbad, CA, USA) was added and the reaction was incubated for $2 \mathrm{~h}$ at $42{ }^{\circ} \mathrm{C}$. The reaction was terminated by adding $0.5 \mathrm{M} \mathrm{NaOH} / 50 \mathrm{mM}$ EDTA and incubated at $65{ }^{\circ} \mathrm{C}$ for $10 \mathrm{~min}$. Finally, the reaction was neutralized with $1 \mathrm{M}$ Tris- $\mathrm{HCl}, \mathrm{pH} 7 \cdot 5$. The cDNA samples were concentrated by centrifugation using Centricon filters (Millipore, Billerica, MA, USA).

\section{cDNA microarray analysis}

The cDNA microarray analysis was performed on rat expression glass microarrays (Genomic Tree, Taejon, Korea), which were spotted with 5000 cDNA of known rat genes and expressed sequence tags (ESTs). A total of 36 microarray slides ( 3 ages $\times 3$ tissue types $\times 4$ replicates) were used to monitor gene expression levels. Hybridization and washing of the microarrays were carried out according to the manufacturer's instructions. In brief, cDNA probe solutions containing $2 \mathrm{X}$ hybridization buffer and Array 50 dT blocker were applied to the microarrays, which were then covered with a spaced glass coverslip and placed in a humidified chamber at $65{ }^{\circ} \mathrm{C}$ for $16 \mathrm{~h}$. Then, the microarrays were sequentially washed for $15 \mathrm{~min}$ each, once at $65^{\circ} \mathrm{C}$ in 2 $\times \mathrm{SSC}$ and $0.2 \% \mathrm{SDS}$, once in $2 \times \mathrm{SSC}$ at room temperature, and once in $0.2 \times \mathrm{SSC}$ at room temperature, and then washed for 2 min at room temperature in $95 \%$ ethanol to fix the cDNA molecules to the probes. Then, the microarrays were centrifuged for $2 \mathrm{~min}$ at 1000 r.p.m. to dry the slide. In preparation for 3DNA hybridization, the 3DNA Capture Reagent and the anti-fade reagent were added to the hybridization buffer. The prepared hybridization buffer was added to the arrays and incubated for $2 \mathrm{~h}$ in a dark humidified chamber at $65^{\circ} \mathrm{C}$. The microarrays were again sequentially washed and dried.

\section{Scanning and data analysis}

The hybridization images were quantitated by GenePix Pro 4.0 (Axon Instruments, Union City, CA, USA). The average fluorescence intensity for each spot was calculated and local background was subtracted. All data normalization and statistical analysis were performed using GeneSpring 6.1 (Silicon Genetics, Redwood, CA, USA). Genes were filtered according to their intensity in the control channel based on the two-component model for estimating variation from control strength (Rocke \& Durbin 2001). Intensity-dependent normalization (LOWESS) was performed, where the ratio was 
reduced to the residual of the LOWESS fit of the intensity vs ratio curve. In addition, to adjust the data from three different ages, we performed median centering by dividing each gene's signal ratio by the median of all the signal ratios for that particular gene. The values of fold change were calculated by dividing the median of normalized signal channel intensity (Cy5) by the median of normalized control channel intensity (Cy3). The ANOVA test (parametric) was performed at $P$ values $<0.05$ to find genes that differentially expressed across conditions. Unsupervised hierarchical cluster analysis was performed by similarity measurements based on Pearson correlations around zero.

\section{Real-time reverse transcription PCR (RT-PCR)}

For real-time RT-PCR, cDNA was prepared from $3 \mu \mathrm{g}$ of total RNA from ZDF or ZLG rats using random hexamers and the Moloney murine leukemia viral reverse transcriptase (Promega, Madison, WI, USA) in a final reaction volume of $20 \mu \mathrm{l}$. The resulting cDNA was analyzed by real-time PCR using SYBR Green PCR core reagents (PE Biosystems, Warrington, UK). PCR was performed in an ABI PRISM 7700 Sequence Detector (Applied Biosystems, Foster City, CA, USA) and each gene-specific primer set was used at concentrations of $150 \mathrm{nM}$ in a final volume of $25 \mu \mathrm{l}$. The accuracy of the PCR products was verified by agarose gel electrophoresis. Quantification of a given gene, expressed as relative mRNA level compared with control levels, was calculated after normalization to $18 \mathrm{~S}$ rRNA and using the $\Delta \Delta \mathrm{C}_{\mathrm{T}}$ formula as described by Perkin Elmer. Individual $\mathrm{C}_{\mathrm{T}}$ values were calculated as means of duplicate or triplicate measurements.

\section{Western blotting}

Skeletal muscle or liver tissues from ZDF (6 and 12 weeks) and ZLC (6 and 12 weeks) rats were solubilized in RIPA buffer (50 mM Tris, pH 7·5, $1 \%$ Nonidet P-40, $150 \mathrm{mM}$ sodium deoxycholate, $150 \mathrm{mM} \mathrm{NaCl}, 1 \mathrm{mM}$ EDTA, $1 \mathrm{mM}$ sodium orthovanadate, $1 \mathrm{mM}$ sodium fluoride, $1 \mathrm{mM}$ phenylmethylsulfonyl fluoride, $1 \mu \mathrm{g} / \mathrm{ml}$ aprotinin, $1 \mu \mathrm{g} / \mathrm{ml}$ leupeptin, and $1 \mu \mathrm{g} / \mathrm{ml}$ pepstatin) for $30 \mathrm{~min}$ on ice. The lysates were clarified by centrifugation and separated by SDS-PAGE (10\%), transferred onto nitrocellulose filter. The filters were probed with SREBP-1 (H-160) or PPAR $\gamma$ (H-100) antibody purchased from Santa Cruz Biotechnology Inc. (Santa Cruz, CA, USA) for $16 \mathrm{~h}$. Membranes were washed and incubated with a 1:4000 dilution of horseradish peroxidase conjugated secondary antibodies. Protein bands were visualized by enhanced chemiluminescence (Amersham Pharmacia Biotech, Piscataway, NJ, USA).

\section{Results}

\section{Overview of gene expression profiles in ZDF rats}

Six-week old ZDF male rats, together with 6-week old ZLG rats serving as controls, were used to study pre-diabetic changes, whereas 12-week old ZDF male rats and age-matched ZLG rats were used to study diabetic changes, and 20-week old ZDF male rats were used to study late-stage diabetic changes. Microarrays were carried out to study gene expression in adipose tissue, skeletal muscle, and liver tissue from ZDF and ZLC rats using cDNA chips containing 5000 rat genes. In this study, four ZDF and ZLC rats at each age were used. Total RNA was isolated from three different tissues from ZDF or ZLC rats of corresponding ages. Four pairs of each Cy5-labeled ZDF and Cy3-labeled ZLC rat cDNA samples were applied to a cDNA chip respectively, which was essentially equivalent as applied in four replications. After performing intensiy-dependent normalization on spots of 12 slides of each tissue (3 ages $\times 4$ replicates), fold-changes were determined by dividing the median normalized signal channel intensity by the median normalized control channel intensity. Differentially expressed genes $(P<0 \cdot 05)$ as determined by ANOVA and with about a 1.3 fold-change in expression levels were selected. Differences observed at 6 weeks, which corresponds to the period preceding diabetes onset, were considered to be involved in causing type 2 diabetes, whereas those seen at 12 weeks were considered likely to be involved in the progression of type 2 diabetes. There were 381 genes found in adipose tissue, 319 genes from skeletal muscle, and 528 genes from liver that exhibits significant changes of expression during type 2 diabetes. These genes were further analyzed using hierarchical clustering to group genes with similar changes in expression profiles. As shown in Fig. 1, hierachical clustering revealed that four replicates showed little variance of expression in each age for the three tissues, indicative of high reliability of chip data. Furthermore, the differentially expressed genes in adipose, skeletal muscle and liver were clustered into 4, 4 , and 5 groups, respectively. Many of the differentially expressed genes in adipose tissue had a similar expression pattern in 6-week old pre-diabetic ZDF rats and 12-week old diabetic ZDF rats, whereas many genes in the liver and skeletal muscle had reverse expression patterns at 6 and 12 weeks of ages. Namely, many of the genes that were up- or downregulated in the liver and skeletal muscle of pre-diabetic ZDF rats became downor upregulated reversely in diabetic 12-week old ZDF rats. Therefore, genes whose expression was differentially regulated from 6 to 12 weeks may contribute to the development of type 2 diabetes, along with up- or downregulated genes found in the tissues of diabetesstage ZDF rats. Tables 1 to 3 list the representative genes in each cluster along with the putative biological 

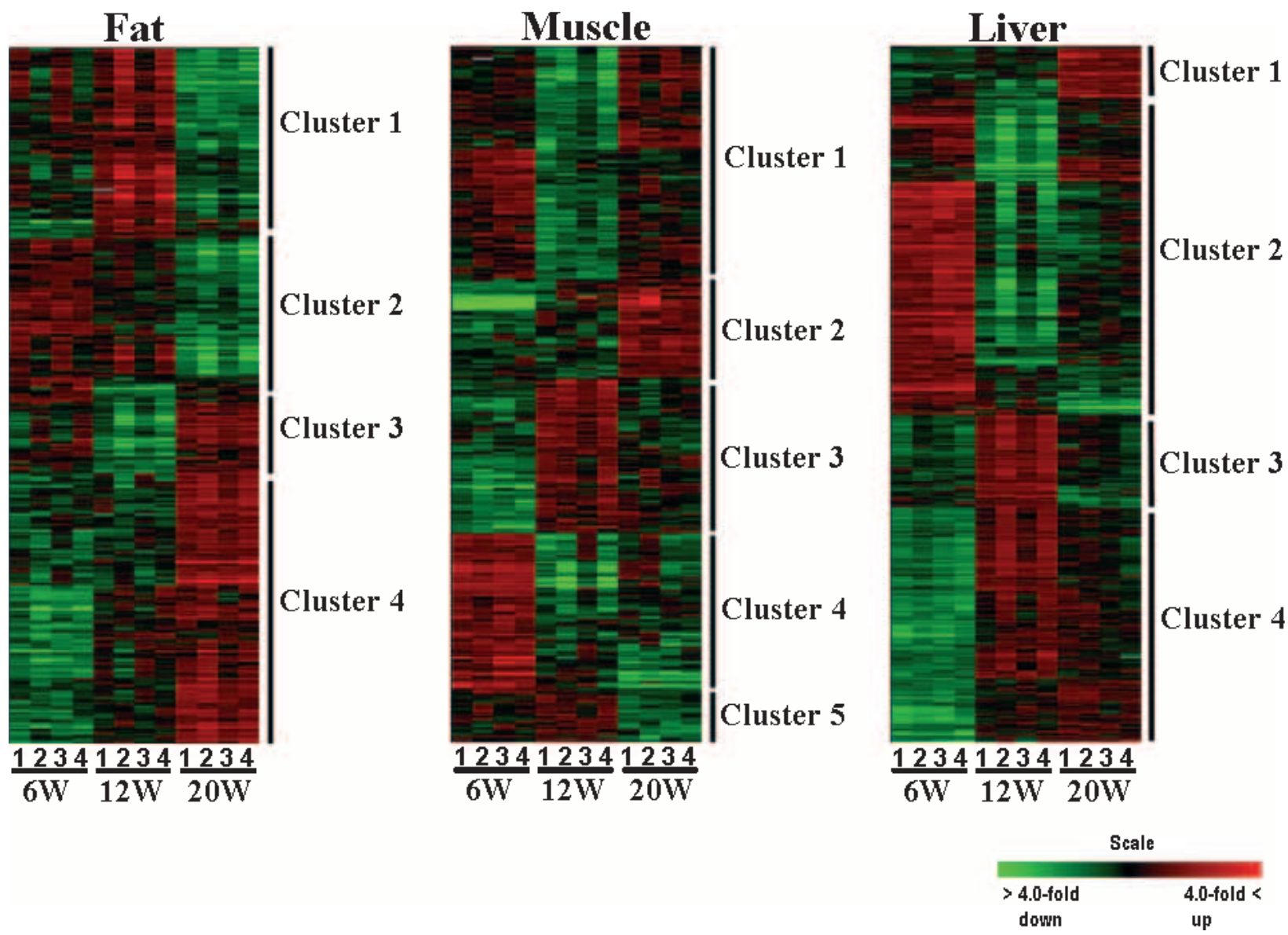

Figure 1 Hierachical Clustering Analysis of differentially expressed genes in insulin sensitive tissues. All replicated ratios of gene expression levels (shown with the Arabic numerals 1 to 4 ) are displayed colorimetically in the three ages (6-week, 6W; 12 -week, $12 \mathrm{~W} ; 20$-week, 20W) old of ZDF rats compared with the control. The scale bar at the bottom represents the relative level of expression of each gene. (Red) Increase and (green) decrease in expression level relative to the median value at specific ages of animals. Details of gene identity and expression differences are given in the Tables 1 to 3 .

functions of their encoded proteins, as found in searches of the public database. Through quantitative real-time RT-PCR, we confirmed expression levels of genes selected on the basis of biological interest or ranking $P$ value in each tissue from cross counterpart animals. As shown in Fig. 2, the expression of genes selected in skeletal muscle and liver was concordant with microarray data, although value differences did not match exactly.

\section{Differentially expressed genes in insulin sensitive tissues of ZDF rats}

In the adipose tissue of ZDF rats, the expresson of serine (or cysteine) proteinase inhibitor 1 (PAI-1) in cluster 1, as a known molecular marker of obesity linked to type 2 diabetes, was increased in diabetic ZDF rats at 12 weeks, consistent with previous reports showing that elevated expression levels of PAI-1 was associated with insulin resistance related to obesity and type 2 diabetes (Bastard et al. 2000). Additionally, PAI has been reported to inhibit insulin signaling by competing with $\alpha \mathrm{v} \beta 3$ integrin for vitronectin binding (Lopez-Alemany et al. 2003), which may explain its role in the development of type 2 diabetes. Furthermore, the expression level of angiotensinogen (AGT) which is involved in blood pressure regulation and adipocyte differentiation, was downregulated in 6-week old pre-diabetic ZDF rats, but upregulated in 12-week old diabetic ZDF rats. Previously, the expression level of AGT in ZDF rats has been reported to be up- or downregulated depending on the age of animals used (Jones et al. 1997, Hainault et al. 2002). Metallothionein 3, identified in cluster 4, which may have an antioxidant role as a metal-binding and stress-response protein, was downregulated in both pre-diabetic and diabetic ZDF rats. The expression of vitamin D binding protein (DBP), essential for cellular endocytosis and intracellular metabolism of vitamin $\mathrm{D}$, 
Table 1 Genes differentially expressed in adipose tissue of ZDF rats

\section{Gene Name}

Accession

Cluster 1

AA901043

AA900150

Al060068

AA955115

Al070183

AA955423

AA859385

AA818904

AA96523

Al044904

AA964578

Al070507

Al059907

Al059648

Al060165

Al136048

Al136365

Cluster 2

AA901405

AA858569

AA963906

AA996833

AA900486

AA818413

Cluster 3

AA925370

AA859785

AA859213

AA819161

AA875489

Cluster 4

AA818559

AA925361

AA819832

AA819638

AA859061

AA859231

AA818706

AA924772

Al058961

AA875488

AA819654

AA899387

AA955420

AA819832

\section{EST}

NAD+-specific isocitrate dehydrogenase b subunit

Fatty acid binding protein 3

Carboxylesterase 3

Nuclear protein 1

Fatty acid binding protein 5 , epidermal

Vimentin

Inhibitor of DNA binding 3, dominant negative

helix-loop-helix protein

Serine (or cysteine) proteinase inhibitor, member 1

Annexin VI

Calpactin I heavy chain

Fibromodulin

Chemokine (C-X-C motif) ligand 10

Angiotensinogen

Lipase, hormone sensitive

3-hydroxy-3-methylglutaryl-Coenzyme A synthase 2

Sortilin1

Protein tyrosine phosphatase, non-receptor type 11

Neuronatin

RNA binding motif protein 16

Aldolase C, fructose-biphosphate

ATP citrate lyase

Clusterin

F-spondin

Alcohol dehydrogenase 1

Stearoyl-Coenzyme A desaturase 2

Desmin

Voltage-dependent anion channel 1

EST

FK506-binding protein 1a

EST

$\mathrm{N}$-acetyltransferase 5

EST

Tropomyosin 1, alpha

Group specific component(vitamin D binding protein)

Metallothionein 3

Microtubule-associated protein $1 \mathrm{~b}$

EST

Similar to zinc finger protein (LOC307362)

Similar to PD2 protein (LOC361531)

Guanylate cyclase 1, soluble, beta 3

Period 1
Normalized expression (ZDF/ZLC)

\begin{tabular}{|c|c|c|c|}
\hline $6 W$ & $12 \mathrm{~W}$ & $20 W$ & Function \\
\hline 0.00 & $1 \cdot 75$ & $-1 \cdot 12$ & Unclassified \\
\hline 0.07 & 1.52 & -1.04 & Metabolism \\
\hline 0.00 & 1.25 & $-0 \cdot 16$ & Metabolism \\
\hline-0.32 & $1 \cdot 17$ & -0.30 & Metabolism \\
\hline$-0 \cdot 24$ & $1 \cdot 10$ & -0.04 & Transcription \\
\hline-0.13 & 0.99 & ND & Metabolism \\
\hline 0.02 & 0.80 & -0.72 & Cytoskeleton \\
\hline$-0 \cdot 14$ & 0.80 & $-0 \cdot 24$ & Transcription \\
\hline 0.09 & 0.69 & $-0 \cdot 68$ & Endopeptidase \\
\hline 0.08 & 0.61 & -0.79 & Calcium binding \\
\hline 0.12 & 0.57 & $-0 \cdot 84$ & Calcium binding \\
\hline 0.03 & 0.51 & -0.63 & Extracellular matrix \\
\hline-0.14 & 0.47 & -0.11 & Signal transduction \\
\hline-1.03 & 0.75 & 0.28 & Endopeptidase \\
\hline-0.55 & 0.72 & ND & Metabolism \\
\hline-0.46 & 0.50 & -0.01 & Metabolism \\
\hline-0.39 & 0.40 & -0.03 & Transport/Endocytosis \\
\hline
\end{tabular}

$\begin{array}{lrll}0.11 & 0.46 & -0.95 & \text { Signal transduction } \\ 0.74 & 0.66 & -0.72 & \text { Unclassified } \\ 0.51 & 0.02 & -0.64 & \text { RNA binding } \\ 0.61 & -0.39 & -0.08 & \text { Metabolism } \\ 0.44 & -0.89 & -0.66 & \text { Metabolism } \\ 0.31 & -0.58 & \text { ND } & \text { Apoptosis }\end{array}$

$\begin{array}{llll}0.04 & -0.97 & 0.79 & \text { Extracellular matrix }\end{array}$

$\begin{array}{llll}0.03 & -0.87 & 0.50 & \text { Metabolism }\end{array}$

$\begin{array}{llll}0.14 & -0.87 & -0.08 & \text { Metabolism }\end{array}$

$\begin{array}{llll}-0.02 & -0.65 & 0.76 \quad \text { Cytoskeleton }\end{array}$

$\begin{array}{llll}0.26 & -0.76 & \text { ND } & \text { Ion channel }\end{array}$

$\begin{array}{rrrl}-0.88 & 0.09 & 0.03 & \text { Unclassified } \\ -0.64 & 0.04 & 0.59 & \text { Signal transduction } \\ -0.59 & 0.00 & 0.86 & \text { Unclassified } \\ -0.59 & 0.06 & 0.77 & \text { Unclassified } \\ -0.51 & -0.01 & 0.47 & \text { Unclassified } \\ -0.46 & -0.18 & 1.32 & \text { Cytoskeleton } \\ -0.64 & -1.08 & -0.01 & \text { Transport } \\ -0.51 & -0.55 & 0.48 & \text { Metal ion binding } \\ -0.68 & 0.05 & 0.61 & \text { Cytoskeleton } \\ -1.20 & -0.04 & 0.84 & \text { Unclassified } \\ -0.59 & 0.04 & 0.33 & \text { Transcription } \\ -1.02 & -0.08 & 0.57 & \text { Unclassified } \\ -0.56 & 0.24 & 0.47 & \text { Signal transduction } \\ -0.59 & 0.00 & 0.86 & \text { Signal transduction }\end{array}$

Expression ratios are shown by $\log _{2}$ scale of normalized mean signal intensities of ZDF rat genes to those of ZLC. ND denotes "non-detectable or low signal-to-noise ratio". W, weeks old.

also was decreased in both pre-diabetic and diabetic ZDF rats. Vitamin D is necessary for maintaining insulin secretion and normal glucose tolerance and influences insulin sensitivity. DBP gene variants have also been shown to be predisposed to type 2 diabetes mellitus (Malecki et al. 2002). Therefore, the decreased expression of DBP is expected to induce insulin resistance. The expression of ATP citrate lyase and stearoyl-coenzyme A desaturase 2 in cluster 2 and 3 respectively, which are involved in triglyceride synthesis, was found to be decreased in 12-week old ZDF rats, whereas lipolytic genes such as hormone sensitive lipase 
Table 2 Genes differentially expressed in skeletal muscle of ZDF rats

Normalized expression (ZDF/ZLC)

\section{Gene Name}

Accession

Cluster 1

AA819345

AA818892

AA963095

AA999182

AA817792

AA924091

AA996896

AA859043

AA858950

AA924933

AA899619

Al028932

Cluster 2

AA900901

AA900958

AA818691

AA817748

AA875328

AA957538

Cluster 3

Al136093

AA924224

AA819300

AA818398

Al072234

AA859122

Al136365

AA900185

AA925173

Cluster 4

AA818605

AA859476

AA819612

AA859814

AA963445

AA899180

AA900899

AA924727

AA901017

AA962987

AA958018

AA819336

AA955881

AA900486

Cluster 5

AA899924

AA924388

AA926010

AA819897

Al070507

Parvalbumin

Prohibitin

EST

Triadin 1

Cyclin F

SorCS2

EST

EST

Sortilin 1

EST

Heparanase

\section{EST}

Cofilin 1

Profilin

Cystatin B

EST

Cathepsin $\mathrm{H}$

Fibromodulin
Pyruvate dehydrogenase

Solute carrier family 10 , member 1

Leprecan-like protein 2

Ubiquitin-conjugating enzyme UBC7

Regulator of G-protein signaling protein 2

Munc13-4 protein

Alpha-globin transcription factor CP2

Prostaglandin F2 receptor negative regulator

Myogenic factor 6

Fas-associated factor 1

Vesicular transport protein rvps45

Fatty acid amide hydrolase $\quad-0.81$

Cytochrome P450, subfamily 11B, polypeptide 2

Squalene epoxidase

Glutathione S-transferase, mu type 3 (Yb3)

p21 (CDKN1A)-activated kinase 1

Selenoprotein P, plasma, 1

$\mathrm{NAD}(\mathrm{P}) \mathrm{H}$ dehydrogenase, quinone 1

Mitogen-activated protein kinase kinase 6

Collagen, type 1 , alpha 1

Carbonyl reductase 1

Cd24 antigen

Fatty acid synthase

ATP citrate lyase

Cd164 antigen

WD repeat domain 20 isoform 1

Fatty acid Coenzyme A ligase, long chain 2

Synuclein, alpha
$6 \mathrm{~V}$

$-0.02$

0.07

$-0.04$

$-0.13$

$-0.01$

$-0.02$

0.39

0.36

0.91

0.08

0.07

0.01

$-2.81$

$-1.78$

$-0.29$

$-1 \cdot 11$

$-0.79$

$-0.60$

$-0.74$

$-0.49$

$-0.49$

$-0.39$

$-0.39$

$-0.12$

$-0.11$

1.41

0.76

0.58

0.57

0.57

0.87

0.76

1.28

1.12

0.97

0.79

0.65

0.32

0.44

0.18

$-0.17$

0.25

0.21

$-0.10$

$12 \mathrm{~W}$

$-1.18$

$-1.05$

$-0.91$

$-0.66$

$-0.48$

$-0.31$

$-0.08$

$-0.65$

$-0.25$

$-0.43$

$-0.81$

$-0.32$

0.06

$-0.13$

0.02

$-0.10$

$-0.03$

$-0.17$

0.12

0.24

0.42

0.35

0.29

0.61

0.40

0.77

0.63

$-0.05$

$-0.28$

$-0.16$

$-0.06$

$-0.20$

$-1.99$

$-1.32$

$-1.04$

$-1.04$

$-0.76$

$-0.72$

$-0.32$

$-0.13$

$-0.89$

1.01

1.00

0.77

0.25

0.32
20W

0.86

0.48

0.68

0.47

0.42

0.83

$-0.12$

0.25

0.05

0.54

0.29

0.19

0.77

0.98

0.57

1.29

0.79

0.54

0.07

$-0.02$

$-0.06$

$-0.08$

0.05

0.05

$-0.03$

$-0.02$

$-0.30$

$-1.23$

$-0.18$

$-0.06$

$-0.24$

$-0.14$

0.02

0.07

$-0.05$

0.12

$-0.05$

$-0.26$

$-0.01$

0.05

$-0.89$

$-0.31$

$-0.84$

0.77

$-0.51$

$-0.50$

Function

Calcium binding

Metabolism

Transcription/cell cycle

Transport

Unclassified

Oxidoreductase/metabolism ubiquitin-conjugating

Translation/exocytosis

Signal transduction

Exocytosis

Transcription

Signal transduction

Cell cycle

Transport/Endocytosis

Transcription

Unclassified

Apoptosis

Transport

Metabolism

Biosynthesis

Oxidoreductase/metabolism

Transferase

Signal transduction

Unclassified

Transport/Endocytosis

Unclassified

Extracellular matrix

Unclassified

Cytoskeleton

Cytoskeleton

Structure

Selenium binding

Oxydoreductase

Signal transduction

Extracellualr matrix

Unclassified

Oxydoreductase/metabolism

Signal transduction

Endopeptidase

Metabolism

Metabolism 
and fatty acid binding proteins in cluster 1 were upregulated at 12 weeks.

In the skeletal muscle of ZDF rats, the expression of pyruvate dehydrogenase and $\mathrm{NAD}(\mathrm{P}) \mathrm{H}$ dehydrogenease for glucose oxidation identified in cluster 1 and 4 respectively, were decreased in 12-week old diabetic ZDF rats. Transgellin 3, whose function is related to muscle development, was also downregulated at 12 weeks, suggesting that this gene may play an important role in insulin resistance and type 2 diabetes since insulin resistance is associated with dysregulated myogenic development. The expression of SorCS2 and sortilin genes in cluster 2 and 3 was decreased in 6-week old pre-diabetic ZDF rats. These genes belong to the novel type I transmembrane receptor family containing a common Vps10 domain, a sorting receptor for the carboxypeptidase Y. It has been suggested that sortilin has a cytoplasmic tail sequence homology between sortilin and insulin like growth factor II (Mazella 2001), and co-localizes in intracellular vesicles containing glucose transporter 4 (GLUT4) and translocates into the plasma membrane in response to insulin (Morris et al. 1998). SorCS2 has an amino acid sequence similar with sortilin except for the presence of isoleucine/valine rich repeats (Hermey et al. 1999). Therefore, the downregulation of $\mathrm{Vps} 10$ domain-containing proteins might influence the translocation of GLUT4 in skeletal muscle. Parvalumin and triadin in cluster 1 , which play an important role in regulating intracellular calcium concentration through their buffering capacity as high-affinity cytosolic calcium binding proteins (CBPs), were significantly downregulated in ZDF rats 12-weeks old. Regulation of intracellular calcium plays a key role in obesity, insulin resistance, and hypertension. Calcium has been shown to regulate insulin signaling, as increasing levels of calcium impairs insulin signaling, possibly through inhibition of insulin-regulated dephosphorylation, resulting in insulin resistance. Therefore, the reduced expression of CBP in diabetic-stage rats may cause an increase in intracellular calcium and lead to insulin resistance.

In the livers of ZDF rats, glucose-6-phosphatase in cluster 3, involved in gluconeogenesis, was upregulated at 12 weeks, which could contribute to hyperglycemia in ZDF rats. Expression of the mitogen activated protein kinase (MAPK) genes, including stress activated protein kinase 2 and MAPK3 (ERK1), identified in cluster 2, was increased at 6 weeks, and the regulator of G-protein signaling 12 was increased at 12 weeks.

\section{Decreased lipogenic gene expression in diabetic liver, but increased lipogenic gene expression in diabetic skeletal muscle of 12-week old ZDF rats}

We found that lipogenic genes, including ATP citrate lyase and fatty acid coenzyme A ligase (FACL), were downregulated in the livers of 12 -week old diabetic ZDF rats. In order to further confirm the reduced expression of lipogenic genes in the livers of diabetic ZDF rats, we measured the expression of other lipogenic genes including fatty acid binding protein (aP2), peroxisome proliferator activated receptor gamma (PPAR $\gamma$ ), and SREBP1c with genes observed in this study at 6 and 12 weeks of age using real-time RT-PCR. As shown in Fig. $3 \mathrm{~A}$, expression levels of aP2, PPAR $\gamma$, and SREBP1c genes were significantly lower in 12-week old ZDF rats compared with 12-week old ZLC rats, consistent with microarray data. The data also showed that the expression of aP2 and PPAR $\gamma$ was increased from 6 to 12 weeks in both strains, but the increase in ZDF rats was much smaller than in ZLC rats. The expression of SREBP1c and FACL2 was increased from 6 weeks to 12 weeks in ZLG rats, whereas the expression was decreased in ZDF rats. Protein expression levels of PPAR $\gamma$ and SREBPl were consistent with the results of real-time RT-PGR (Fig. 3C).

In contrast to the decreased lipogenic gene expression found in diabetic livers of ZDF rats, the expression of the lipogenic genes, fatty acid coenzyme A ligase, fatty acid synthase, and ATP citrate lyase, were increased in the skeletal muscle of 12-week old diabetic ZDF rats. Expression of other lipogenic genes including PPAR $\gamma$, SREBP1c, and stearoyl-coenzyme A desaturase 1 (SCD1) were also measured in the skeletal muscle at 6 and 12 weeks of age with real-time RT-PCR. As shown in Fig. 3B, the expression of SCD1 and FACL2 was significantly higher in the skeletal muscle of 12-week old ZDF rats compared with ZLC rats of the same age. Even though expression of PPAR $\gamma$ and SREBP1c was not shown to be significantly different between ZLC and ZDF rats at 12 weeks of age, the expression of these genes in diabetic ZDF rats was increased from 6 weeks to 12 weeks in contrast to decreases observed in ZLG rats. The protein levels of PPAR $\gamma$ and SREBP1 were also consistent with transcription levels (Fig. 3C).

\section{Reduced expression of antioxidant genes and CYP450 genes in diabetic livers from 12-week old ZDF rats}

Our microarray data also revealed that antioxidant genes, such as hemopexin, glutathione peroxidase 1, superoxide dismutase 1 , and glutaredoxin 1 were downregulated in the liver of ZDF rats at 12 weeks of age. Furthermore, the expression of cytochrome P450 (CYP) genes, including CYP4A3, CYP1A2, CYP3A9, and CYP2C39 was also significantly decreased at 12 weeks, although the expression of these genes was increased at 6 weeks. These data strongly suggest that the liver of diabetic ZDF rats at 12 weeks of age has an impaired capacity to manage oxidative stress and some xenobiotics. Therefore, we verified the expression of 
Table 3 Genes differentially expressed in liver of ZDF rats

Normalized expression (ZDF/ZLC)

\section{Gene Name}

Accession

Cluster 1

AA859607

AA900933

AA965012

AA924800

Cluster 2

AA859455

AA900766

AA998956

Al059997

AA818904

AA955475

AA925792

AA923836

AA964788

AA875555

AA866249

AA818124

AA818680

AA818180

AA818043

Al145654

AA926256

AA924591

AA900486

AA926359

AA925350

AA901404

AA926010

AA923919

AA818406

AA875311

AA859087

AA925794

AA819042

AA859963

Al136404

AA859354

AA818813

AA819611

AA955662

AA819911

AA819465

AA924594

Cluster 3

AA964628

Al072234

Al144577

AA964507

AA924223

AA926047

AA924063

Al059788

Sir2-like 3

EST alpha

Neuritin

EST subunit

EST

Cathepsin E

Dynactin

Hemopexin
Sterol-C4-methyl oxidase-like

14-3-3 protein epsilon isoform

Zinc finger protein 354A

3-hydroxy-3-methylglutaryl-Coenzyme A synthase 1

Abl-interactor 2

Stress activated protein kinase alpha II

Inhibitor of DNA binding 3, dominant negative

helix-loop-helix protein

Ubiquitin-conjugating enzyme E2D 2

Superoxide dismutase 1

Eukaryotic initiation factor 5 (elF-5)

Glutathione peroxidase 1

Protein kinase, mitogen activated 3 (ERK1)

RAB4A, member RAS oncogene family

Cytochrom P450 15-beta gene

Ornithine aminotransferase

Murine thymoma viral (v-akt) oncogene homolog 2

Cytochrome P450, 2c39

Protein kinase, cAMP dependent regulatory, type I,

Cytochrome P450 4A3

ATP citrate lyase

Insulin-like growth factor binding protein, acid labile

Fatty acid Coenzyme A ligase, long chain 2

U6 snRNA-associated Sm-like protein LSm6

Collagen, type V, alpha 2

Diazepam binding inhibitor

Cytochrome oxidase subunit VIc

Cytochrome P450 3A9

$G$ protein gamma- 5 subunit

Glutaredoxin 1 (thioltransferase)

Insulin-like growth factor binding protein 3

Apolipoprotein C-I

Integrin beta 1

Apolipoprotein C-III

Cytochrome P450, 1a2

Glucose-6-phosphatase, catalytic

p21 (CDKN1A)-activated kinase 1

Regulator of G-protein signaling 12

Inhibitor of DNA binding 2, dominant negative

helix-loop-helix protein

Pyroglutamyl-peptidase I

Vacuolar protein sorting 35

Mitogen activated protein kinase kinase 1

Folate hydrolase

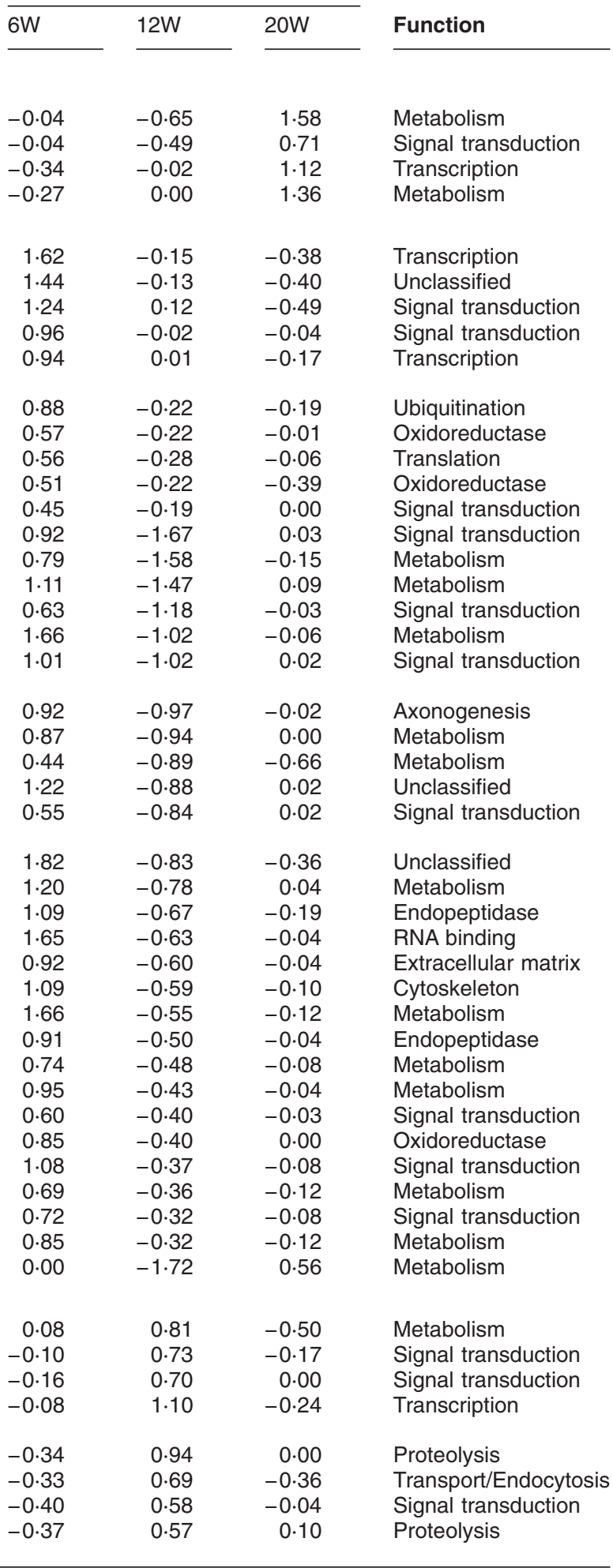


Table 3 Continued

\begin{tabular}{|c|c|c|c|c|c|}
\hline \multirow[b]{3}{*}{$\begin{array}{l}\text { Accession } \\
\text { Cluster } 4\end{array}$} & \multirow[b]{2}{*}{ Gene Name } & \multicolumn{3}{|c|}{ Normalized expression (ZDF/ZLC) } & \multirow[b]{2}{*}{ Function } \\
\hline & & $6 \mathrm{~W}$ & $12 \mathrm{~W}$ & $20 \mathrm{~W}$ & \\
\hline & & & & & \\
\hline AA859109 & EST & -0.80 & 0.72 & -0.01 & Unclassified \\
\hline Al145353 & Thyroid hormone receptor alpha & -0.72 & 0.57 & 0.05 & Signal transduction \\
\hline AA964978 & Phosphofructokinase, muscle & -0.63 & 0.61 & -0.08 & Metabolism \\
\hline AA819072 & Sgk & -0.56 & 0.48 & ND & Signal transduction \\
\hline AA817985 & EST & -0.55 & 0.63 & -0.02 & Unclassified \\
\hline AA900733 & $\begin{array}{l}\text { Nuclear factor of kappa light chain gene enhancer in } \\
\text { B-cells inhibitor, alpha }\end{array}$ & $-0 \cdot 76$ & 0.35 & $0 \cdot 22$ & Signal transduction \\
\hline AA900759 & T-cell death associated gene & -0.76 & 0.42 & 0.01 & Apoptosis \\
\hline AA819663 & $\begin{array}{l}\text { Acyl-CoA:dihydroxyacetonephosphate } \\
\text { acyltransferase }\end{array}$ & -0.93 & 0.01 & 0.08 & Metabolism \\
\hline AA924572 & Kinesin family member 5B & $-1 \cdot 12$ & 0.60 & $-0 \cdot 11$ & Cytoskeleton \\
\hline AA901272 & EST & $-0 \cdot 75$ & 0.30 & 0.11 & Unclassified \\
\hline AA924837 & Bone morphogenetic protein receptor, type $1 \mathrm{~A}$ & -0.66 & 0.39 & 0.11 & Signal transduction \\
\hline AA819622 & Coagulation factor II receptor & $-1 \cdot 19$ & 0.22 & 0.03 & Signal transduction \\
\hline AA925531 & Prolactin-like protein $\mathrm{B}$ & -0.66 & 0.12 & $0 \cdot 21$ & Hormone \\
\hline AA965187 & Lactalbumin, alpha & -0.58 & 0.23 & 0.01 & Metabolism \\
\hline
\end{tabular}

Expression ratios are shown by $\log _{2}$ scale of normalized mean signal intensities of ZDF rat genes to those of ZLC. ND denotes "non-detectable or low signal-to-noise ratio". W, weeks old.

gluthathione-related genes and CYP 450 genes in both animals at 6 and 12 weeks of ages with the real-time RT-PCR. As shown in Fig. 4, the expression of glutathione peroxidase 1, superoxide dismutase, and glutaredoxin 1 was decreased in the liver of 12 -week old diabetic ZDF rats compared with ZLG rats of the same age, consistent with microarray data. Moreover, the expression of these genes was significantly decreased from 6 weeks to 12 weeks in ZDF rats, whereas the expression was increased in ZLC rats. The expression of CYP4A3, 1A2, 3A9 and 2C39, as shown in Fig. 5, was also decreased in 12-week old ZDF rats.

\section{Common genes expressed concurrently in insulin sensitive tissues of ZDF rats}

Several common genes expressed concurrently in insulin sensitive tissues of ZDF rats were observed (Table 4). Of them, calpain 4 was downregulated in skeletal muscle and liver of 12-week old rats but in all three tissues of 20-week old diabetic ZDF rats. Annexin 1, cathespsin B, and vimentin were upregulated in both pre-diabetic muscle and liver tissue from ZDF rats, but their expression was decreased in diabetic-stage animals. Lumican and enolase 2 were also upregulated in both pre-diabetic adipose and skeletal muscle in ZDF rats, whereas collapsing response mediator protein 1 was significantly downregulated in both pre-diabetic tissue types. Growth associated protein 43, collagen (type 1 a1), and transgelin 3 were downregulated in both diabetic adipose and skeletal muscle although the expression was increased in pre-diabetic rats. The expression of protein phosphatase 5 was increased in both diabetic adipose and pre-diabetic liver tissues.

\section{Discussion}

Using microarray technology, it is now possible to examine the transcriptional profile of several thousand genes simultaneously to decipher the pathophysiology of the disease at molecular level. In this study, we assessed the expression profiles of 5000 genes in insulin sensitive tissues from 6-week old pre-diabetic ZDF rats, 12-week old diabetic ZDF rats, and 20-week old late-stage diabetic ZDF rats for a better fundamental understanding of insulin resistance and type 2 diabetes, Collectively, our results suggest a pathophysiological cascade of gene expression in type 2 diabetes in the ZDF model.

Lipolytic gene expression was increased in the adipose tissue of 12-week old diabetic ZDF rats. Increased free fatty acids (FFA) released by adipocytes is a key feature in type 2 diabetes. Since the balance between cellular triglyceride synthesis, FFA re-esterification, and triglyceride hydrolysis determines the amount of FFA released by adipocytes, aberrations in these cellular pathways may contribute to increased FFA production in adipose tissue. Elevated plasma concentrations of FFA can cause insulin resistance by impairing the ability of insulin to stimulate muscle glucose uptake and to inhibit hepatic glucose production (Lewis et al. 2002). Lipolysis in 
A 6 weeks muscle

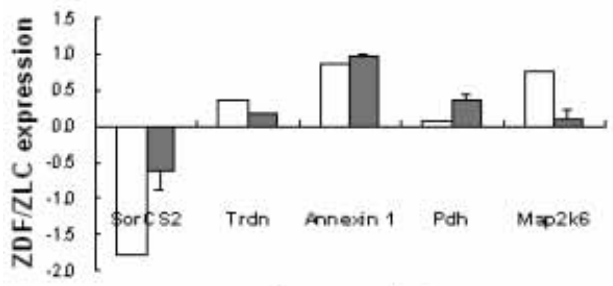

Gene symbol

\section{6 weeks liver}

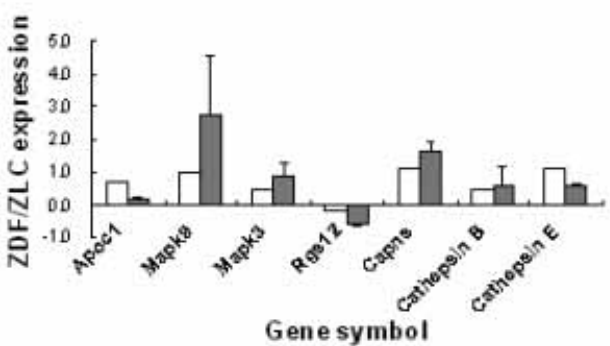

B 12 weeks muscle

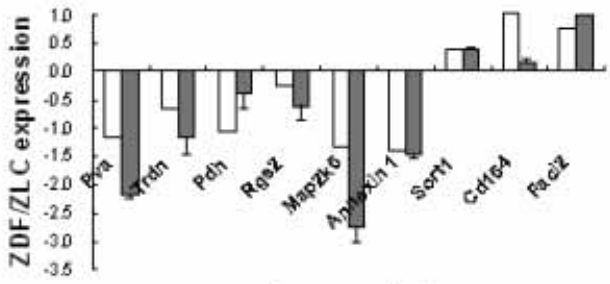

Gene symbol

Figure 2 Relative expression of select transcripts from the skeletal muscle and liver tissue of ZDF or ZLC rats by real-time RT-PCR. Total RNA was extracted from the skeletal muscle or liver of 6- and 12-week old rats, and PCR reactions were carried out in SYBR PCR core reagents. The y-axis is $\Delta \Delta \mathrm{C}_{\mathrm{T}}$ calculated after normalization to $18 \mathrm{~S}$ rRNA or corresponding relative expression level of ZDF to ZLC rats under the microarray experiments. Grey bars, $\Delta \Delta \mathrm{C}_{\mathrm{T}}$; open bars, relative expression level $\left(\log _{2}\right.$ scale) under the microarray experiments. Individual $C_{\mathrm{T}}$ values are representative of means from triplicate measurements. Trdn, triadin 1; Pdh, pyruvate dehydrogenase; Map2k6, mitogen-activated protein kinase kinase 6, Pva, parvalbumin; Rgs2, regulator of G-protein signaling protein 2; Sort1, sortilin; Facl2, fatty acid coenzyme A ligase, long chain 2; Apoc1, apolipoprotein C-I; Mapk9, mitogen activated protein kinase 9; Mapk3, mitogen activated protein kinase 3; Rgs12, regulator of G-protein signaling protein 12; Capns, calpain, small subunit 1; Hpx, hemopexin.

adipose tissue is mediated, in part, via interaction of fatty acid binding protein (FABP) with hormone sensitive lipase (Lewis et al. 2002). In our data, ATP citrate lyase and stearoyl-coenzyme A desaturase 2, involved in triglyceride synthesis, were downregulated in adipose tissue of 12-week old ZDF rats, whereas lipolytic genes such as hormone sensitive lipase and FABP were upregulated at 12 weeks. This imbalance may increase the release of FFA from adipose tissue in diabetic ZDF rats and could lead to further insulin resistance and development of type 2 diabetes.

While lypolytic gene expression was increased in the adipose tissues of 12-week old diabetic ZDF rats, the expression of genes involved in lipogenesis was decreased in the liver as well as in the adipose tissue of diabetic ZDF rats at 12 weeks. Reportedly, adipose function, reflected in the expression of lipogenic genes, deteriorates with prolonged obesity (Nadler et al. 2000) and reduced lipogenic adipocytes are associated with increased hepatic lipogenesis, which may be a shift in the lipogenic burden from adipocytes to other organs such as the liver (Diraison et al. 2002). However, a failure to increase hepatic lipogenesis in obesity has been shown to contribute to the development of type 2 diabetes (Lan et al. 2003). Moreover, increased hepatic lipogenesis is also associated with reduced risk of diabetes in a lipoatrophic mouse model (Colombo et al. 2003). In our study, the expression of ATP citrate lyase and fatty acid coenzyme A ligase for lipogenesis was significantly downregulated in the liver of 12-week old diabetic ZDF rats although the expression was increased in 6-week old pre-diabetic rats. The expression of other lipogenic genes such as aP2, PPAR $\gamma$, and SREBP1c also decreased significantly in 12-week old ZDF rats compared with 12-week old ZLC rats, which is shown in Fig. 3A and 3C. Previous reports also showed that lipogenic gene expression in the 
A Liver


SREB P 10

B Muscle
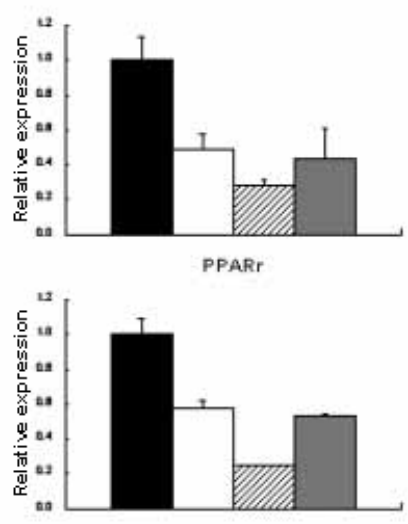

SREBF10
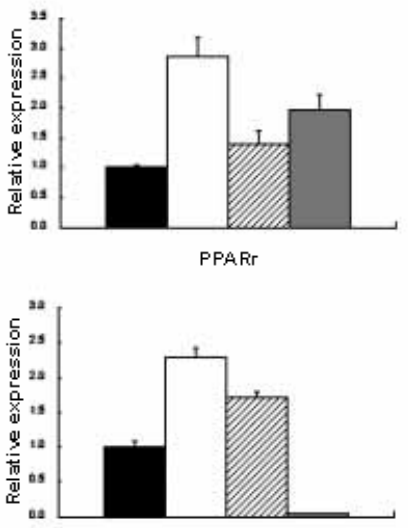

FACL2

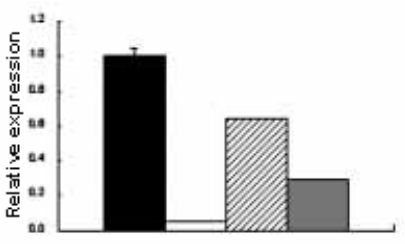

$\operatorname{sco} 1$

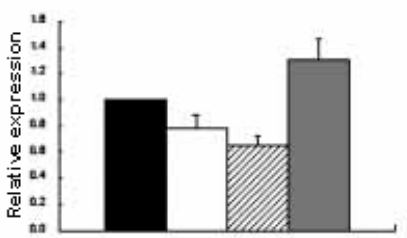

FACL2
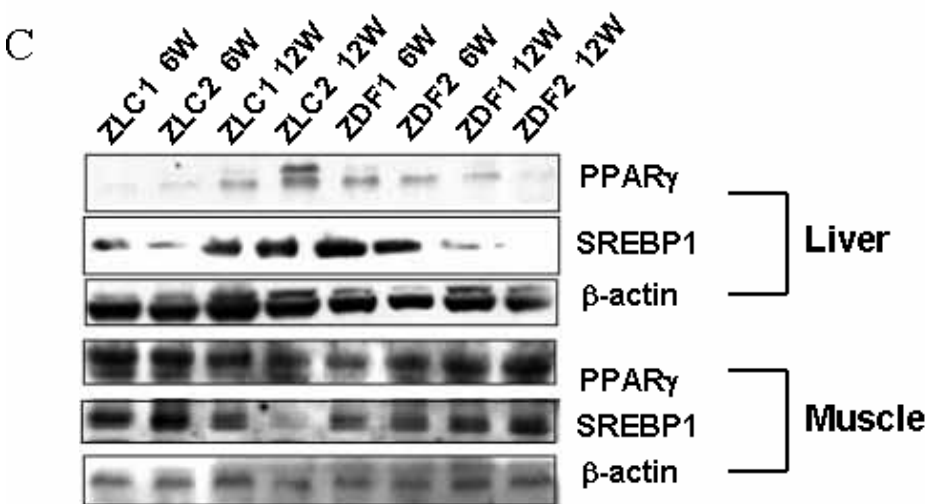

Figure 3 Quantitative expression of lipogenic genes in the liver or skeletal muscle at 6 weeks or 12 weeks of age. Total RNA was extracted from the 6- and 12-week old liver (A) or 6- and 12-week-old skeletal muscle (B) of ZDF and ZLC rats, and the PCR reactions were carried out in SYBR PCR core reagents. The y-axis is the relative expression level normalized against the mean expression level (2 $\triangle C$ T value) in 6-week old ZLC rats. Black bars, 6-week-old ZLC rats; open bars, 12-week-old ZLC rats; hatched bars, 6-week old ZDF rats; grey bars,12-week old ZDF rats. Liver and muscle tissues of two ZDF and ZLC rats were solubilized and Western blotted with PPAR $\gamma$ or SREBP1 or $\beta$-actin antibody (C). aP2, adipocyte fatty acid-binding protein; PPAR $\gamma$, peroxisome proliferator activated receptor gamma; SREBP1c, sterol regulatory element-binding protein 1c; Facl2, fatty acid coenzyme A ligase, long chain 2; SCD1, stearoyl-CoA desaturase 1. 

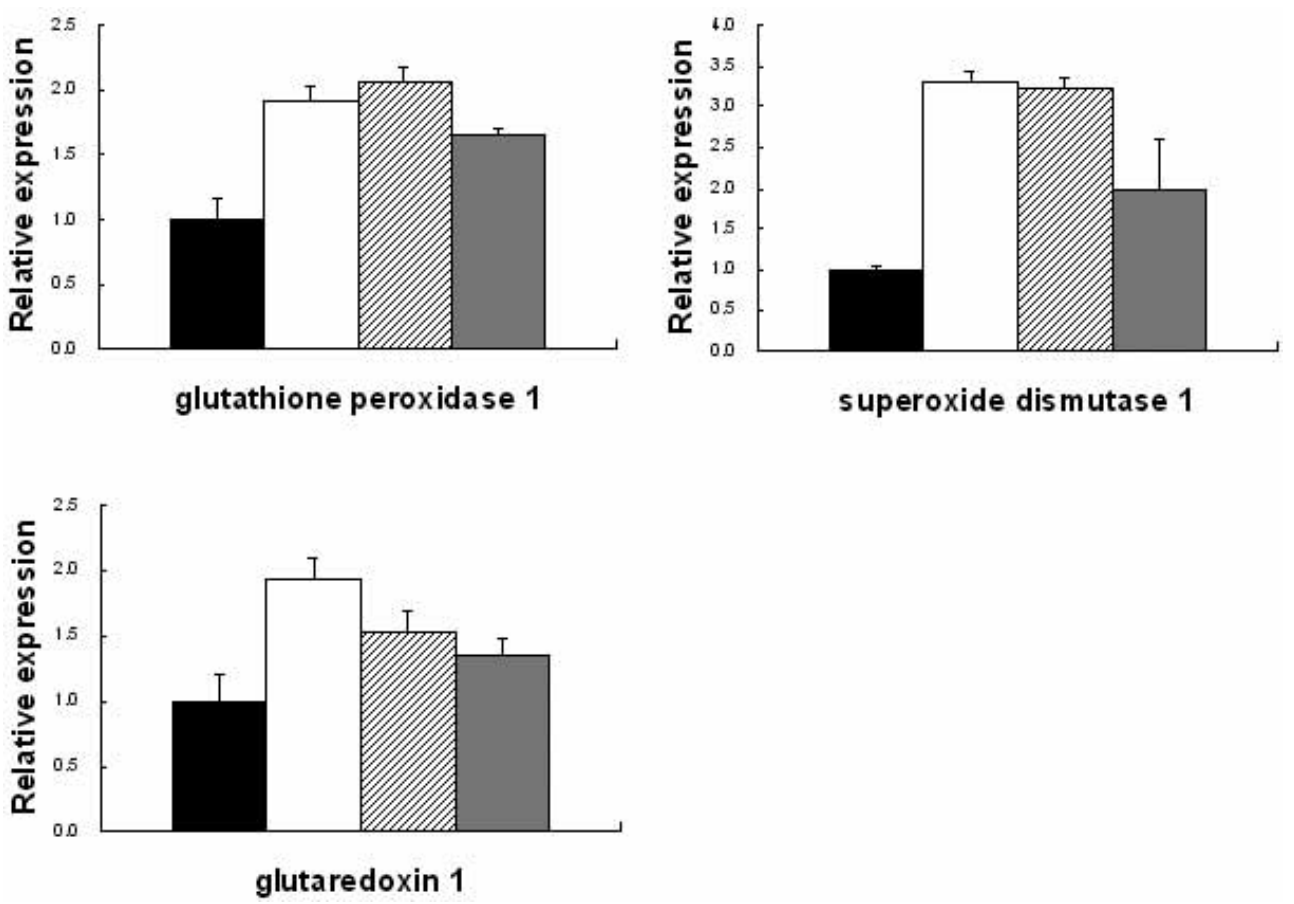

Figure 4 Quantitative expression of antioxidant genes in the liver at 6 weeks and 12 weeks of age. Total RNA was extracted from the 6-week old liver or 12-week old liver of ZDF and ZLC rats, and the PCR reactions were carried out in SYBR PCR core reagents. The y-axis is the relative expression level normalized against the mean expression level $\left(2^{\Delta C T}\right.$ value) in 6 -week old ZLC rats. Black bars, 6-week old ZLC rats; open bars, 12-week old ZLC rats; hatched bars, 6-week old ZDF rats; grey bars, 12-week old ZDF rats.

livers of diabetes-susceptible BTBR-ob/ob was decreased compared with diabetes-resistant B6 ob/ob animals, in addition to a dramatic decrease of the expression from 6 weeks (pre-diabetes) to 14 weeks (diabetes) in BTBR-ob/ob (Lan et al. 2003). These results suggested that the livers of ZLG rats maintain a high level of hepatic lipogenesis at 12 weeks, whereas lipogenesis in the diabetic livers of ZDF rats was impaired in the transition from the pre-diabetes to diabetes stage. Therefore, the impairment of hepatic lipogenesis in diabetic ZDF rats may contribute to the progression of type 2 diabetes by increasing glucose production and shifting lipogenic burdens to skeletal muscle with deteriorated adipose function.

With impairment of lipogenesis in the livers of 12-week old ZDF rats, we observed an increase in the expression of lipogenic genes, including fatty acid synthase, ATP citrate lyase, and fatty acid coenzyme A ligase in the skeletal muscle of diabetic ZDF rats at 12 weeks of age. Expression of other lipogenic genes, including PPAR $\gamma$, SREBP1c, and SCD1 also was increased in the skeletal muscle of 12 -week old ZDF rats compared with ZLC rats of the same age as shown in Fig. 3B and 3C. Moreover, expression of these lipogenic genes was increased from 6 weeks to 12 weeks, whereas the expression was decreased in ZLC rats. Potentially, these increases could contribute to muscular triglyceride accumulation, leading to insulin resistance or type 2 diabetes. With intramuscular lipid accumulation, lipid intermediates such as long-chain fatty acyl CoA, diacylglycerol, and ceramide are increased. Increasing lipid intermediates inhibit insulin signaling and insulinmediated glucose uptake in skeletal muscle (Petersen \& Shulman 2002, Schmitz-Peiffer 2002, Lam et al. 2003). Therefore, upregulated lipogenesis in the skeletal muscle of diabetic stage animals could contribute to the development of obesity-related diabetes.

Increased hepatic gluconeogenic gene expresson in the livers of 12-week old diabetic ZDF rats was observed, as well as reduced gene expression of glucose oxidation in the skeletal muscle and adipose tissue of ZDF rats at 12 weeks. Expression of glucose-6phosphatase was increased in the liver of ZDF rats at 12 weeks of age, resulting in hyperglycemia. The committed step for glucose oxidation is the conversion of pyruvate to acetyl CoA in the mitochondria by the pyruvate dehydrogenase complex, which then enters the TCA cycle. In our study, expression of pyruvate dehydrogenase (PDXl) and $\mathrm{NADP}(\mathrm{H})$ dehydrogenase was decreased in the skeletal muscle of diabetic ZDF 

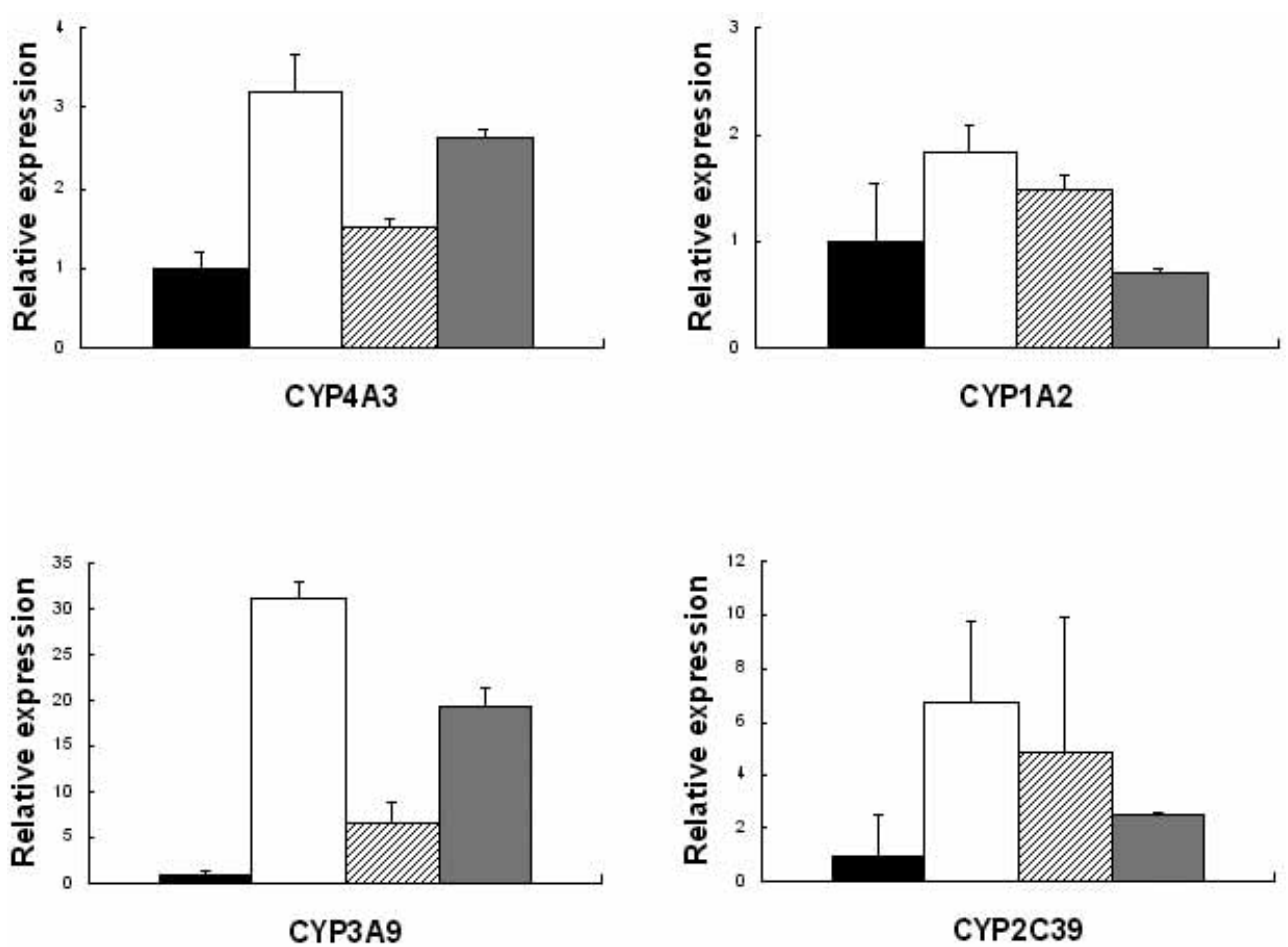

Figure 5 Quantitative expression of CYP genes in the liver at 6 weeks and 12 weeks of age. Total RNA was extracted from the 6-week or 12-week old liver of ZDF and ZLC rats, and PCR reactions were carried out in SYBR PCR core reagents. The y-axis is the relative expression level normalized against the mean expression level $\left(2^{\triangle C T}\right.$ value) in 6-week old ZLC rats. Black bars, 6-week-old ZLC rats; open bars, 12-week-old ZLC rats; hatched bars, 6-week-old ZDF rats; grey bars,12-week-old ZDF rats.

rats, and voltage-dependent anion channel for oxidative phosphorylation was also decreased in the adipose tissue of diabetic ZDF rats. These results suggest that oxidative metabolism is decreased in both skeletal muscle and adipose tissue of diabetic ZDF rats at 12 weeks of age.

The expression of antioxidant genes was downregulated in adipose and liver tissues of 12-week old diabetic ZDF rats. More recently, studies have linked reactive oxygen species (ROS) production and oxidative stress to insulin resistance (Evans et al. 2002). In vitro, ROS and oxidative stress led to the activation of multiple serine kinase cascades, which phosphorylates insulin-signaling substrates including the insulin receptor (IR) and insulin receptor substrate (IRS)-1, and inhibits tyrosine phosphorylation (Evans et al. 2002). Therefore, antioxidants could prevent the activation of these serine kinases induced by ROS and oxidative stress. In our study, metallothionein 3, which plays a role as an antioxidant protecting ROS, as well as a detoxifying antidote for metals, was downregulated in the adipose tissues of ZDF rats at both ages. Hemopexin (Hpx), which acts as an antioxidant through its strong heme binding, was also downregulated in liver of diabetic ZDF rats progressing from pre-diabetes to diabetes. Importantly, the expres- sion of glutathione-related defense genes including glutathione peroxidase 1 , superoxide dismutase 1 , and glutaredoxin 1 was increased in the livers of 6 -week old pre-diabetic ZDF rats which may be responsible for defenses against oxidative stress, but was significantly reduced at 12 weeks (diabetes stage). We verified the expression of these genes in both animals at each age with real-time RT-PCR. As shown in Fig. 4, expression levels in ZLG rats were increased from 6 weeks to 12 weeks, whereas expression in ZDF rats was significantly decreased. Therefore, the reduced expression of these antioxidant genes in diabetic livers may partly account for insulin resistance and development of type 2 diabetes.

Although the expression of cytochrome P450 (CYP) was increased in 6-week old pre-diabetic ZDF rats, CYP450 expression was significantly reduced in the livers of 12-week old diabetic ZDF rats. Cytochrome P450 constitutes a superfamily of heme-proteins that play important roles in the detoxification of numerous xenobiotics, as well as endogeneous compounds including steroids, fatty acids, and prostaglandins. In various disease states, including diabetes, obesity, and inflammation and infection, the expression of hepatic 
Table 4 Concurrent expressed genes in adipose tissue, skeletal muscle and liver of ZDF rats

\begin{tabular}{|c|c|c|c|c|c|}
\hline & Tissue & $6 \mathrm{~W}, \mathrm{NE}$ & $12 W, N E$ & 20W, NE & Description \\
\hline \multicolumn{6}{|c|}{$\begin{array}{l}\text { Accession } \\
\text { Muscle \& liver }\end{array}$} \\
\hline \multirow[t]{2}{*}{ AA875382 } & muscle & -0.17 & 0.47 & -0.41 & calbindin 1 \\
\hline & liver & 1.07 & -0.64 & 0.02 & \\
\hline \multirow[t]{2}{*}{ AA819452 } & muscle & 0.72 & -0.27 & -0.09 & transgelin \\
\hline & liver & 0.54 & -0.08 & -0.25 & \\
\hline \multirow[t]{2}{*}{ AA963225 } & muscle & 0.66 & $-0 \cdot 16$ & -0.07 & cathepsin B \\
\hline & liver & 0.47 & $-0 \cdot 16$ & -0.04 & \\
\hline \multirow[t]{2}{*}{ AA963445 } & muscle & 0.57 & -0.20 & -0.14 & selenoprotein $\mathrm{P}$, plasma, 1 \\
\hline & liver & 0.65 & -0.51 & 0.03 & \\
\hline \multirow[t]{2}{*}{ AA859385 } & muscle & 0.68 & -0.63 & -0.23 & vimentin \\
\hline & liver & 0.87 & -0.20 & -0.07 & \\
\hline \multirow[t]{2}{*}{ AA924402 } & muscle & 0.48 & -0.29 & -0.54 & general transcription factor Ila, 2 \\
\hline & liver & 0.98 & -0.54 & -0.26 & \\
\hline \multirow{2}{*}{ AA964960 } & muscle & 0.87 & -1.39 & -0.26 & annexin 1 \\
\hline & liver & 0.82 & -0.98 & -0.78 & \\
\hline \multicolumn{6}{|c|}{ Muscle \& fat } \\
\hline \multirow[t]{2}{*}{ AA925443 } & muscle & -0.39 & 0.63 & $-0 \cdot 17$ & cellular retinoic acid binding protein 2 \\
\hline & fat & -0.70 & 0.00 & 0.94 & \\
\hline \multirow[t]{2}{*}{ AA924564 } & muscle & -1.98 & -0.01 & 0.63 & mitochondrial ribosomal protein L11 \\
\hline & fat & $-1 \cdot 12$ & -0.04 & $1 \cdot 24$ & \\
\hline \multirow[t]{2}{*}{ AA998065 } & muscle & $-2 \cdot 14$ & 0.03 & 0.90 & collapsin response mediator protein 1 \\
\hline & fat & -1.72 & -0.07 & 0.61 & \\
\hline \multirow[t]{2}{*}{ AA866389 } & muscle & 0.56 & -0.43 & 0.01 & lumican \\
\hline & fat & 0.53 & -0.08 & -0.53 & \\
\hline \multirow{2}{*}{ AA924727 } & muscle & 1.28 & -1.04 & -0.05 & collagen, type 1 , alpha 1 \\
\hline & fat & 0.71 & -0.54 & -0.65 & \\
\hline \multirow[t]{2}{*}{ AA997308 } & muscle & 0.45 & -0.27 & -0.08 & enolase 2 , gamma \\
\hline & fat & 0.45 & -0.35 & -0.24 & \\
\hline \multirow[t]{2}{*}{ Al043649 } & muscle & $1 \cdot 28$ & -0.85 & $-0 \cdot 18$ & growth associated protein 43 \\
\hline & fat & 0.71 & -0.72 & $-0 \cdot 17$ & \\
\hline \multirow[t]{2}{*}{ Al044424 } & muscle & 0.71 & $-1 \cdot 16$ & -0.23 & transgelin 3 \\
\hline & fat & 0.68 & -0.62 & -0.28 & \\
\hline \multicolumn{6}{|l|}{ Fat \& liver } \\
\hline \multirow[t]{2}{*}{ AA818443 } & fat & -0.01 & -0.25 & 0.65 & dipeptidylpeptidase 4 \\
\hline & liver & 0.80 & -0.76 & 0.00 & \\
\hline Al072330 & fat & 0.13 & 0.38 & -0.52 & lactate dehydrogenase $\mathrm{A}$ \\
\hline & liver & 1.31 & -0.05 & -0.38 & \\
\hline AA925017 & fat & 0.05 & 0.65 & -0.58 & chemokine (C-X-C motif) ligand 11 \\
\hline & liver & 0.72 & -0.55 & -0.01 & \\
\hline AA956187 & fat & 0.06 & 0.60 & -1.05 & protein phosphatase $\mathrm{V}$ \\
\hline & liver & 0.67 & -0.43 & 0.00 & \\
\hline Al145101 & fat & -0.03 & 0.60 & -0.80 & hydroxyacyl glutathione hydrolase \\
\hline & liver & 0.70 & -0.83 & 0.00 & \\
\hline Muscle \& I & \& fat & & & & \\
\hline AA900053 & muscle & 0.97 & -0.32 & $-0 \cdot 14$ & calpain, small subunit 1 \\
\hline & fat & 0.30 & 0.41 & $-1 \cdot 24$ & \\
\hline & liver & $1 \cdot 11$ & -0.63 & -0.32 & \\
\hline AA925675 & muscle & 1.06 & -0.85 & -0.06 & collagen, type III, alpha 1 \\
\hline & fat & 0.72 & -0.05 & -0.38 & \\
\hline & liver & 0.96 & -0.52 & -0.15 & \\
\hline AA875221 & muscle & 0.98 & -0.07 & -1.07 & isocitrate dehydrogenase 3 , gamma \\
\hline & fat & -0.20 & $1 \cdot 10$ & $-0 \cdot 12$ & \\
\hline & liver & 1.14 & -0.99 & 0.04 & \\
\hline
\end{tabular}

Expression ratios are shown by $\log _{2}$ scale of normalized mean signal intensities of ZDF rat genes to those of ZLC. NE denotes "Normalized Expression(ZDF/ZLC)". W, weeks old. 
P450 in the liver changes markedly. In streptozotocininduced diabetes, hepatic expression of CYP2B, CYP2E1, and CYP1A2 was increased, but expression of GYP2G11, GYP2G13, CYP2A2, and CYP3A2 was decreased (Thummel \& Schenkman 1990). In New Zealand obese mice, which exhibit a polygenic syndrome of obesity, insulin resistance, dyslipidemia, and hypertension, the expression of CYP2B9, CYP3A16, and CYP4A14 was increased markedly in livers from diabetic mice, but only slightly increased in insulin resistant mice. In contrast, expression of CYP2C22, CYP2C29 and CYP2C40 was reduced in diabetic, but not affected in insulin resistant mice. Furthermore, expression of CYP1A2 and CYP7B1 was reduced in both diabetic and insulin resistant mice (Pass et al. 2002). In our present study, expression of GYP4A3, CYP3A9, CYP2C39, and CYP1A2 was increased in the livers of pre-diabetic ZDF rats, but was significantly reduced in diabetic livers, which was confirmed by real-time RT-PCR (Fig. 5). Although these alterations correlated with changes in serum free fatty acid levels and seem to be mediated by PPAR- $\alpha$, the reduction of these CYP enzymes in diabetic livers of ZDF rats may contribute to the development of type 2 diabetes due to a reduced capacity for xenobiotic detoxification.

Analyzing microarray data, we found that the expresson of MAP serine/threonine kinase pathway genes was up- or downregulated depending on the tissue type. Stress activated protein kinase (SAPK) alpha 2 (referred to as JNK/SAPK) and extracellular signal regulated kinase 1 (ERK-1) were upregulated in the livers of 6-week old pre-diabetic ZDF rats, but mitogen activated protein kinase kinase 6 (MKK6), which activates p38 MAPK, was downregulated in the skeletal muscle of ZDF rats at 12 weeks of age. It was reported that constitutive activation of MEK1-ERK downregulates the expression of GLUT4, IR, IRS-1 and IRS-2, resulting in marked impairment of insulininduced tyrosine phosphorylation of IRS-1 and IRS-2, docking of the p85 $\alpha$ regulatory subunit of PI3K, and PI3K activation (Hirosumi et al. 2002). Furthermore, the activation of MKK7-JNK pathway also suppressed tyrosine phosphorylation of IRS-1 or IRS-2, which in turn, suppressed activation of PI3K and Akt. It was also reported that JNK/SAPK activity is abnormally elevated in obesity (Hirosumi et al. 2002). Taken together, activation of ERK, JNK can induce insulin resistance in pre-diabetic livers. Previous reports demonstrated that the p38 MAPK inhibitor, SB203580, prevented insulin-stimulated glucose uptake in 3T3-L1 adipocyte and L6 muscle cells (Sweeney et al. 1999) and that alpha lipoic acid activated glucose uptake via a p38 MAPK-dependent pathway (Konrad et al. 2001). Therefore, downregulation of MKK6, upstream of p38 MAPK, may lead to decreased insulin-stimulated glucose transporter in diabetic skeletal muscle.
We also observed several common genes regulated differentially in insulin sensitive tissues including annexin, regulator of G-protein signaling (RGS), and calpain 4. Annexin 1 was upregulated in the skeletal muscle and livers of pre-diabetic ZDF rats. The annexin superfamily, which consists of at least 11 different, abundant, and ubiquitously expressed proteins, reportedly play important roles in the regulation of insulin secretion and the effects of insulin on its target tissues by inhibition of IR tyrosine phosphorylation (Melki et al. 1994). Furthermore, it was reported that the annexin 1 gene harbors variants that increase the risk of type 2 diabetes (Lindgren et al. 2001). All together, upregulation of annexin 1 in pre-diabetic skeletal muscle and liver tissue may induce insulin resistance and contribute to the development of type 2 diabetes. Additionally, expression of the regulator of G-protein signaling (RGS) gene, which is essential for catecholamine and insulin action, was increased in pre-diabetic skeletal muscle and diabetic liver tissue in $\mathrm{ZDF}$ rats. The $\mathrm{G}$ protein signaling pathway is regulated by the interplay between receptor-catalyzed activation and inhibitory RGS proteins. RGS proteins acts like a GTPase-activating protein (GAP) specific for $\mathrm{Gi}$ and $\mathrm{Gq}$ class $\mathrm{G}$ protein alpha subunit, and plays a crucial role in processes responsible for shutting off G-protein-mediated cell responses in eukaryotes (Ishii \& Kurachi 2003). Recent observations have found possible linkages between heterotrimeric G-proteins and insulin signaling (Luft 1997). Reportedly, the G alpha-q/ 11 protein is required for insulin-induced glucose transport in 3T3-L1 adipocyte in PI3-kinase dependent or independent signal transduction pathways (Imamura et al. 1999). Therefore, the upregulation of RGS in insulin sensitive tissues could attenuate insulin stimulated GLUT4 translocation by inhibiting signaling by GTP binding protein, and lead to insulin resistance in the pre-diabetic and diabetic stages. Another cysteine proteinase, calpain 4, was downregulated in the skeletal muscle and liver of 12-week old diabetic ZDF rats, although the expression was increased in 6-week old pre-diabetic ZDF rats. Recently, one member of the calpain family, calpain 10, was identified by positional cloning as a susceptibility gene for type 2 diabetes. Genetic studies have shown that variations in the calpain gene are associated with type 2 diabetes (Horikawa et al. 2000). Furthermore, low levels of calpain 10 mRNA in skeletal muscle has also been reportedly associated with insulin resistance (Baier et al. 2000). Treatment of muscle strips with the calpain inhibitor, ALLM and E-64-d resulted in a significant reduction in the rate of insulin-stimulated glucose uptake and the incorporation of glucose into glycogen (Sreenan et al. 2001). Therefore, the reduction of calpain 4 gene expression from pre-diabetes to diabetes in insulin sensitive tissues may also attenuate the insulin-stimulated glucose uptake and 
play an important role in the development of type 2 diabetes.

In summary, we assessed global transcriptional profiles of insulin sensitive tissues of ZDF male rats at a pre-diabetic and diabetic stage. This approach, coupled with current metabolic knowledge, provided several candidate genes and molecular pathology of insulin resistance and the development of type 2 diabetes.

\section{Acknowledgements}

We thank Dr Van-Anh Nguyen for critical review of the manuscript. This work was supported by the intramural grant of the National Institute of Health, Korea.

The array data have been submitted to the GEO data repository (http://www.ncbi.nlm.nih.gov/geo/) under accession no. GSE1080.

\section{References}

Baier LJ, Permana PA, Yang X, Pratley RE, Hanson RL, Shen GQ, Mott D, Knowler WC, Cox NJ, Horikawa Y, Oda N, Bell GI \& Bogardus C 2000 A calpain-10 gene polymorphism is associated with reduced muscle mRNA levels and insulin resistance. Fournal of Clinical Investigation 106 R69-R73.

Bastard JP, Pieroni L \& Hainque B 2000 Relationship between plasma plasminogen activator inhibitor 1 and insulin resistance. Diabetes Metabolism Research and Reviewes 16 192-201.

Colombo C, Haluzik M, Cutson JJ, Dietz KR, Marcus-Samuels B, Vinson C, Gavrilova O \& Reitman ML 2003 Opposite effects of background genotype on muscle and liver insulin sensitivity of lipoatrophic mice. Role of triglyceride clearance. Fournal of Biological Chemistry 278 3992-3999.

Diraison F, Dusserre E, Vidal H, Sothier M \& Beylot M 2002 Increased hepatic lipogenesis but decreased expression of lipogenic gene in adipose tissue in human obesity. American fournal of Physiology. Endocrinology and Metabolism 282 E46-E51.

Evans JL, Goldfine ID, Maddux BA \& Grodsky GM 2002 Oxidative stress and stress-activated signaling pathways: a unifying hypothesis of type 2 diabetes. Endocrine Reviews 23 599-622.

Hainault I, Nebout G, Turban S, Ardouin B, Ferre P \& Quignard-Boulange A 2002 Adipose tissue-specific increase in angiotensinogen expression and secretion in the obese $(\mathrm{fa} / \mathrm{fa})$ Zucker rat. American Fournal of Physiology. Endocrinology and Metabolism 282 E59-E66.

Hermey G, Riedel IB, Hampe W, Schaller HC \& Hermans-Borgmeyer I 1999 Identification and characterization of SorCS, a third member of a novel receptor family. Biochemical and Biophysical Research Communications 266 347-351.

Hirosumi J, Tuncman G, Chang L, Gorgun CZ, Uysal KT, Maeda K, Karin M \& Hotamisligil GS 2002 A central role for JNK in obesity and insulin resistance. Nature 420 333-336.

Horikawa Y, Oda N, Cox NJ, Li X, Orho-Melander M, Hara M, Hinokio Y, Lindner TH, Mashima H, Schwarz PE, Bosque-Plata L, Horikawa Y, Oda Y, Yoshiuchi I, Colilla S, Polonsky KS, Wei S, Concannon P, Iwasaki N, Schulze J, Baier LJ, Bogardus C, Groop L, Boerwinkle E, Hanis CL \& Bell GI 2000 Genetic variation in the gene encoding calpain-10 is associated with type 2 diabetes mellitus. Nature Genetics 26 163-175.

Imamura T, Vollenweider P, Egawa K, Clodi M, Ishibashi K, Nakashima N, Ugi S, Adams JW, Brown JH \& Olefsky JM $1999 \mathrm{G}$ alpha-q/11 protein plays a key role in insulin-induced glucose transport in 3T3-L1 adipocytes. Molecular and Cellular Biology 19 6765-6774.

Ishii M \& Kurachi Y 2003 Physiological actions of regulators of G-protein signaling (RGS) proteins. Life Sciences 74 163-171.

Jones BH, Standridge MK \& Moustaid N 1997 Angiotensin II increases lipogenesis in 3T3-L1 and human adipose cells. Endocrinology 138 1512-1519.

Konrad D, Somwar R, Sweeney G, Yaworsky K, Hayashi M, Ramlal T \& Klip A 2001 The antihyperglycemic drug alpha-lipoic acid stimulates glucose uptake via both GLUT4 translocation and GLUT4 activation: potential role of p38 mitogen-activated protein kinase in GLUT4 activation. Diabetes $\mathbf{5 0}$ $1464-1471$.

Lam TK, Carpentier A, Lewis GF, van de Werve G, Fantus IG \& Giacca A 2003 Mechanisms of the free fatty acid-induced increase in hepatic glucose production. American Fournal of Physiology. Endocrinology and Metabolism 284 E863-E873.

Lan H, Rabaglia ME, Stoehr JP, Nadler ST, Schueler KL, Zou F, Yandell BS \& Attie AD 2003 Gene expression profiles of nondiabetic and diabetic obese mice suggest a role of hepatic lipogenic capacity in diabetes susceptibility. Diabetes $\mathbf{5 2}$ 688-700.

Lewis GF, Carpentier A, Adeli K \& Giacca A 2002 Disordered fat storage and mobilization in the pathogenesis of insulin resistance and type 2 diabetes. Endocrine Reviewes 23 201-229.

Lindgren CM, Nilsson A, Orho-Melander M, Almgren P \& Groop LC 2001 Characterization of the annexin I gene and evaluation of its role in type 2 diabetes. Diabetes 50 2402-2405.

Lopez-Alemany R, Redondo JM, Nagamine Y \& Munoz-Canoves P 2003 Plasminogen activator inhibitor type-1 inhibits insulin signaling by competing with alphavbeta3 integrin for vitronectin binding. European Fournal of Biochemistry 270 814-821.

Luft FC 1997 G-proteins and insulin signaling. Fournal of Molecular Medicine 75 233-235.

Malecki MT, Klupa T, Wanic K, Cyganek K, Frey J \& Sieradzki J 2002 Vitamin D binding protein gene and genetic susceptibility to type 2 diabetes mellitus in a Polish population. Diabetes Research and Clinical Practice 57 99-104.

Mazella J 2001 Sortilin/neurotensin receptor-3: a new tool to investigate neurotensin signaling and cellular trafficking? Cell Signalling 13 1-6.

Melki V, Hullin F, Mazarguil H, Fauvel J, Ragab-Thomas JM \& Chap H 1994 Annexin I as a potential inhibitor of insulin receptor protein tyrosine kinase. Biochemical and Biophysical Research Communications 203 813-819.

Mootha VK, Lindgren CM, Eriksson KF, Subramanian A, Sihag S, Lehar J, Puigserver P, Carlsson E, Ridderstrale M, Laurila E, Houstis N, Daly MJ, Patterson N, Mesirov JP, Golub TR, Tamayo P, Spiegelman B, Lander ES, Hirschhorn JN, Altshuler D \& Groop LC 2003 PGC-1 alpha-responsive genes involved in oxidative phosphorylation are coordinately downregulated in human diabetes. Nature Genetics 34 267-273.

Morris NJ, Ross SA, Lane WS, Moestrup SK, Petersen CM, Keller SR \& Lienhard GE 1998 Sortilin is the major 110-kDa protein in GLUT4 vesicles from adipocytes. Fournal of Biological Chemistry 273 3582-3587.

Nadler ST, Stoehr JP, Schueler KL, Tanimoto G, Yandell BS \& Attie AD 2000 The expression of adipogenic genes is decreased in obesity and diabetes mellitus. PNAS 97 11371-11376.

Pass GJ, Becker W, Kluge R, Linnartz K, Plum L, Giesen K \& Joost HG 2002 Effect of hyperinsulinemia and type 2 diabetes-like hyperglycemia on expression of hepatic cytochrome p450 and glutathione s-transferase isoforms in a New Zealand obese-derived mouse backcross population. Fournal of Pharmacology and Experimental Therapeutics 302 442-450.

Petersen KF \& Shulman GI 2002 Pathogenesis of skeletal muscle insulin resistance in type 2 diabetes mellitus. American fournal of Cardiology $9011 \mathrm{G}-18 \mathrm{G}$. 
Rocke DM \& Durbin B 2001 A model for measurement error for gene expression arrays. Foumal of Computational Biology 8 557-569.

Rome S, Clement K, Rabasa-Lhoret R, Loizon E, Poitou C, Barsh GS, Riou JP, Laville M \& Vidal H 2003 Microarray profiling of human skeletal muscle reveals that insulin regulates approximately 800 genes during a hyperinsulinemic clamp. Fournal of Biological Chemistry 278 18063-18068.

Saltiel AR 2001 New perspectives into the molecular pathogenesis and treatment of type 2 diabetes. Cell 104 517-529.

Schmitz-Peiffer C 2002 Protein kinase C and lipid-induced insulin resistance in skeletal muscle. Annals of the New York Academy of Sciences 967 146-157.

Sreekumar R, Halvatsiotis P, Schimke JC \& Nair KS 2002 Gene expression profile in skeletal muscle of type 2 diabetes and the effect of insulin treatment. Diabetes 51 1913-1920.

Sreenan SK, Zhou YP, Otani K, Hansen PA, Currie KP, Pan CY, Lee JP, Ostrega DM, Pugh W, Horikawa Y, Cox NJ, Hanis CL, Burant CF, Fox AP, Bell GI \& Polonsky KS 2001 Calpains play a role in insulin secretion and action. Diabetes $502013-2020$
Sweeney G, Somwar R, Ramlal T, Volchuk A, Ueyama A \& Klip A 1999 An inhibitor of p38 mitogen-activated protein kinase prevents insulin-stimulated glucose transport but not glucose transporter translocation in 3T3-L1 adipocytes and L6 myotubes. Fournal of Biological Chemistry 274 10071-10078.

Thummel KE \& Schenkman JB 1990 Effects of testosterone and growth hormone treatment on hepatic microsomal P450 expression in the diabetic rat. Molecular Pharmacology $\mathbf{3 7}$ $119-129$.

Yang X, Pratley RE, Tokraks S, Bogardus C \& Permana PA 2002 Microarray profiling of skeletal muscle tissues from equally obese, non-diabetic insulin-sensitive and insulin-resistant Pima Indians. Diabetologia 45 1584-1593.

Received 9 November 2004

Accepted 13 December 2004

Made available online as an Accepted Preprint 17 December 2004 